\title{
21
}

\section{A Geospatial Analysis of the Social, Economic and Environmental Dimensions and Drivers of Poverty in South-West Coastal Bangladesh}

Fiifi Amoako Johnson and Craig W. Hutton

\subsection{Introduction}

What are the causes of persistent poverty in the Ganges-BrahmaputraMeghna (GBM) delta and how important are environmental dimensions and ecosystem services in explaining the uneven distribution of the observed rates of poverty? Investigation of the fine-grained linkages between the distribution of poverty and the state and health of the environment are particularly important for policy decisions and planning for the allocation of resources for development intervention. In this research, spatially aggregated population level data are used to (i) examine the extent

\section{F. Amoako Johnson ( $\bowtie)$}

Social Statistics and Demography, Faculty of Social, Human and Mathematical Sciences, University of Southampton, Southampton, UK

C. W. Hutton

Geodata Institute, Geography and Environment, University of Southampton, Southampton, UK 
of geographical variations in poverty in the delta, (ii) identify the key socio-economic and environmental drivers of poverty and (iii) investigate how the drivers of poverty are spatially distributed and associated with spatially explicit socio-economic and environmental factors. Underlying the approach adopted is the hypothesis that if changes in the socio-economic and environmental functions in deltas have a substantial impact on the well-being of the local population, it should be reflected in the associated poverty levels measured.

Research has revealed wide social and geographical variations in poverty in Bangladesh (Amoako Johnson et al. 2016). In addition to the social, economic and cultural determinants, recent studies have shown that environmental and ecosystem services are also important associative factors of poverty (Suich et al. 2015; Amoako Johnson et al. 2016; Islam et al. 2016). Suich et al. (2015) also documented that ecosystem services act as a safety net for the poor and marginalised populations; however there is little evidence to suggest that availability of ecosystem services acts as a route out of poverty (see Chap. 2). Other studies have shown that the impact of ecosystem services on poverty are mediated by other factors including access to land, land tenure arrangements and availability of human capital (McKay and Lawson 2003; Daw et al. 2016). Yet, the ambiguity about the causes of the uneven distribution of poverty across space and across society remains unexplained. In this research, the hypothesis that the spatial dynamics of the factors associated with poverty including environmental services and human capital affect the incidence of poverty across space is explored.

Conventional approaches for measuring poverty (poverty headcount, income share and the poverty gap) rely on indicators such as income, expenditure and/or consumption which are either not covered by censuses or, where they are reported, are often not reliable (Meyer and Sullivan 2003; Nicoletti et al. 2011). To overcome these limitations, studies have used approaches based on households' ownership of assets and amenities (e.g. Filmer and Pritchett 2001). Validation of these approaches have shown that asset poverty robustly captures the multidimensionality of poverty (Filmer and Pritchett 2001) and represents chronic poverty and lack of human capital (McKay and Lawson 2003; Cooper and Bird 2012; Stein and Horn 2012; Wietzke 2015). 
Most censuses in low- and middle-income countries collect detailed information on ownership of assets and amenities, which could be used to evaluate the poverty status of local communities and the associative effects of climate-related hazards and environmental stressors.

In this chapter, socio-economic data from the Bangladesh Population and Housing Census (BPHC) is linked with environmental data derived from Landsat Imagery to examine the geospatial differentials in poverty with social, economic and environmental vulnerability, including salinisation, development of shrimp and prawn farms, loss of agriculture, water logging and infrastructure development in the GBM delta. The geospatial unit of analysis is the Union, which is the lowest tier of local level administrative structure in Bangladesh and typically represent perhaps 5,000 people.

\subsection{Background}

Although deltas are major source of diverse ecosystem services, vital for sustaining human well-being, they remain exposed to the impacts of climate change, environmental hazards, sea-level rise and land cover changes on local ecosystems. In turn, livelihoods and survival of residents, particularly poor and vulnerable communities, are affected (Nicholls et al. 2016). Communities of the GBM delta are therefore not only marginalised by environmental dynamics but also in their social and economic development. This is reflected in the region's adult illiteracy rate, education, access to health care, nutrition, employment, transportation and gender empowerment indicators which remain very low, with high geographical inequalities (Biswas 2008). For example, a study by Szabo et al. (2016) reported large intra-urban inequalities in education and access to health care services, whilst a study by Sohel et al. (2010) identified clusters of high foetal loss and infant death in the localities of the Meghna River.

A major challenge to the ecosystem services within the delta has been the increasing salinisation of the region which has had a substantial impact on land use and land cover changes. This is illustrated by the decline of traditional (rice) agriculture and the increase in brackish 
shrimp farming (although freshwater prawn farming also has a 20-year history within the area). Shrimp farming, due to the high demand and perceived monetary benefits, is an economic adaptation to the impacts of the rapidly salinising delta with many farmers converting their permanently flooded farmlands into shrimp farms and others actively encouraging saline water from marine sources into their farmlands to enable shrimp production (Rahman et al. 2013). Large-scale commercial shrimp farming in the delta has also developed, leading to deforestation, loss of agricultural land and increasing soil toxicity. For the local population, this has generated issues around land tenure, livelihood displacements, income loss, food insecurity and negative health impacts, loss of rural unemployment, social unrest, conflicts and forced migration (Paul and Vogl 2011; Swapan and Gavin 2011; Hossain et al. 2013). These issues raise concerns on the benefits and sustainability of the everexpanding shrimp farms to the vulnerable and marginalised populations of the delta.

Analysis of historical data also shows a decline in mangrove areas of about 17 per cent in the Sundarbans of the GBM delta, through both sea-level rise and deforestation (see Chap. 26 and Mukhopadhyay et al. (2015)), with projections anticipating a further decline of between 3 and 24 per cent by 2100 (Nicholls et al. 2016). Alongside salinisation and land loss, waterlogging of agricultural land is a growing phenomenon in the study area and is the result of the slow dissipation of annual flooding due to poorly maintained and overwhelmed drainage systems. These changes have important implications for provisioning ecosystem services (e.g. agriculture, fisheries) and regulating services such as the protective role of mangroves during storms.

Evidently, there is the need to examine the complex interactions between the socio-economic and environmental dynamics of the GBM delta to support policy and programmes aimed at alleviating poverty and develop sustainable approaches to preserve the regions' ecosystems and environment. In this research, multiple data sources including Census, Landsat Satellite Imagery 5 TM and Soil Salinity Survey data are used to examine the extent of geospatial clustering in poverty in the delta and their associative relationships with selected socio-economic and environmental factors in the GBM delta. 


\subsection{Study Area}

The analysis is conducted at the Union level, which is the lowest local government administrative unit in Bangladesh (Panday 2011; MoHFW 2012). The spatial distribution of Unions is shown in Fig. 21.2. The study area focused on the south-central (Barisal, Bhola and Patuakhali districts) and south-western (Bagerhat, Barguna, Jhalokati, Khulna, Pirojpur and Satkhira districts) coastal zones of the Bangladeshi GBM delta (Fig. 21.1).

The study area covers the 653 Unions which make up the central and western coastal zones of the GBM delta, classified into 497 rural and 156 urban (cities, municipalities and Upazila headquarters) Unions. It is important to note that four of the nine districts in the study area (Bagerhat, Satkhira, Pirojpur and Khulna) are classified amongst the major shrimp-producing districts in Bangladesh (FAO 2015).

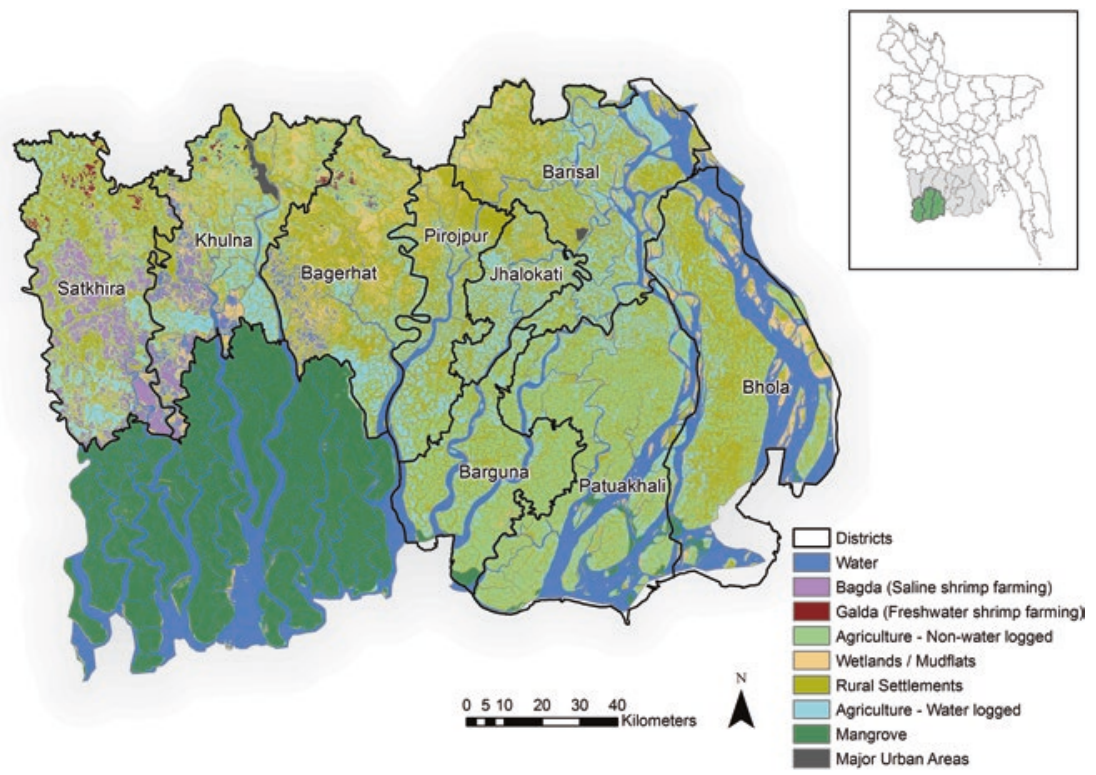

Fig. 21.1 South-central and south-western coastal zones of the Bangladeshi GBM delta. Map shows districts and land use (Reproduced from Amoako Johnson et al. 2016 under Creative Commons Attribution 4.0 International License (http:// creativecommons.org/licenses/by/4.0/)) 


\subsection{Data and Methodology}

\subsubsection{Socio-economic Data}

Unlike environmental and climate-related data which can be generated across multiple spatial resolutions, social and economic data is more problematic as the infrastructure and resources to conduct surveys to collect data representative for small geographic areas are limited. A major source of representative local level social and economic data for most low- and middle-income countries is therefore the national Population and Housing Census (PHC). ${ }^{1}$ In Bangladesh, although these censuses are less regular and expensive compared to population level surveys, they do provide important demographic and human capital information representative for small geographic units such as Unions.

The outcome variable of interest 'asset poverty' is a multidimensional score based on ownership of assets and amenities derived from the 2011 Bangladesh PHC (BBS 2012). The assets and amenities data include detailed information on the type of housing structure (pucka, semi-pucka, kutcha and jhupri), sources of drinking water (tap, tube well and others), type of toilet facility (water sealed, non-water sealed, non-sanitary and no toilet) and electricity connectivity. Pucka refers to houses built with permanent materials such as burnt bricks or concrete, kutcha are those built with nondurable materials such mud floors and metal sheet roofs and/or walls, whilst semi-pucka is a hybrid of pucka and kutcha (e.g. floors and/ or walls are bricks or concrete but the rest are sheets) (Bern et al. 1994; Nenova 2010; GFDRR et al. 2014). A maximum likelihood factor analysis technique (Filmer and Pritchett 2001; Rutstein and Johnson 2004) is used to derive an asset poverty score at Union level. Maximum likelihood factor analysis is used as it circumvents the problem of multicollinearity and assigns indicator weights based on the variations in ownership of assets and amenities (Jones and Andrey 2007). The first factor score is categorised into quintiles and mapped to show the extent of spatial clustering in asset poverty.

The 2011 Bangladesh PHC also collected detailed information on demographic, economic, human capital and tenure. The socio-economic covariates derived from the 2011 Bangladesh PHC include employment 
status, adult literacy, school attendance, population density, dependency ratio and average household size. Information on major road density in each Union was derived from the 2011 Bangladesh Department of Roads and Highways data.

\subsubsection{Environmental Data}

The environmental covariates for the analysis are derived from 2009 Bangladesh Soil Salinity Survey (BSSS) (Ahsan 2010) and the 2010 Bangladesh Landsat 5 TM supplemented with the Bangladesh 2010 MODIS Terra Satellite Imagery (MODIS TSI). The 2009 BSSS is used to derive the percentage of Union area affected by soil salinity, whilst the Landsat 5 TM remote sensing images is used to extract Union area used for brackish shrimp and freshwater prawn farming. Union area affected by soil salinity is classified into four intensities: (i) low salinity (2-4 deciSiemens per metre $(\mathrm{dS} / \mathrm{m})$ ), (ii) moderate salinity (4.1-8 dS/m), (iii) high salinity $(8.1-12 \mathrm{dS} / \mathrm{m})$ and (iv) very high salinity $(12 \mathrm{dS} / \mathrm{m}$ or higher). The percentage of Union area used for brackish shrimp farming is classified into four categories: (i) no brackish shrimp farming, (ii) low brackish shrimp farming (less than one per cent of Union area), (iii) moderate brackish shrimp farming (one to ten per cent of Union area) and (iv) high brackish shrimp farming (greater than ten per cent of Union area). The percentage of Union area used for freshwater prawn farming was categorised into three categories: Unions with (i) no freshwater prawn farming, (ii) low freshwater prawn farming (less than one per cent of Union area) and (iii) high freshwater prawn farming (greater than one per cent of Union area). It is important to note that freshwater prawn farming is very limited in the study area, with only eight Unions where more than ten per cent of the Union area used for freshwater prawn farming. Additional environmental predictors extracted from the Landsat 5 TM include (i) the waterlogged agricultural land in a Union, (ii) Union area that is mangrove forest, (iii) permanent open water bodies and (iv) wetland and mudflats (see Amoako Johnson et al. 2016 for a more detailed discussion on the variables and their extraction). Table 21.1 shows the environmental, socioeconomic and important controls variables selected for the analysis. 


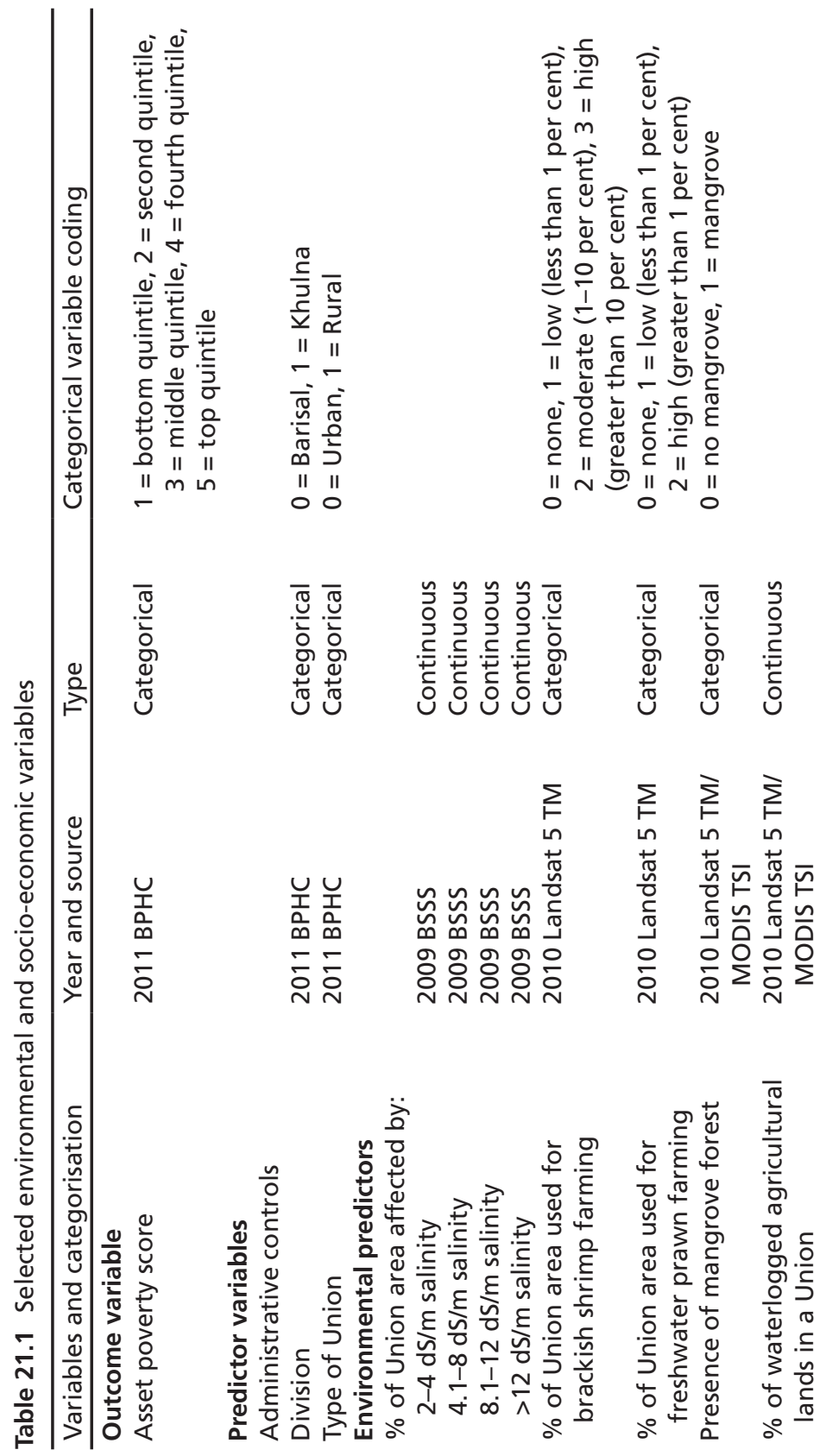




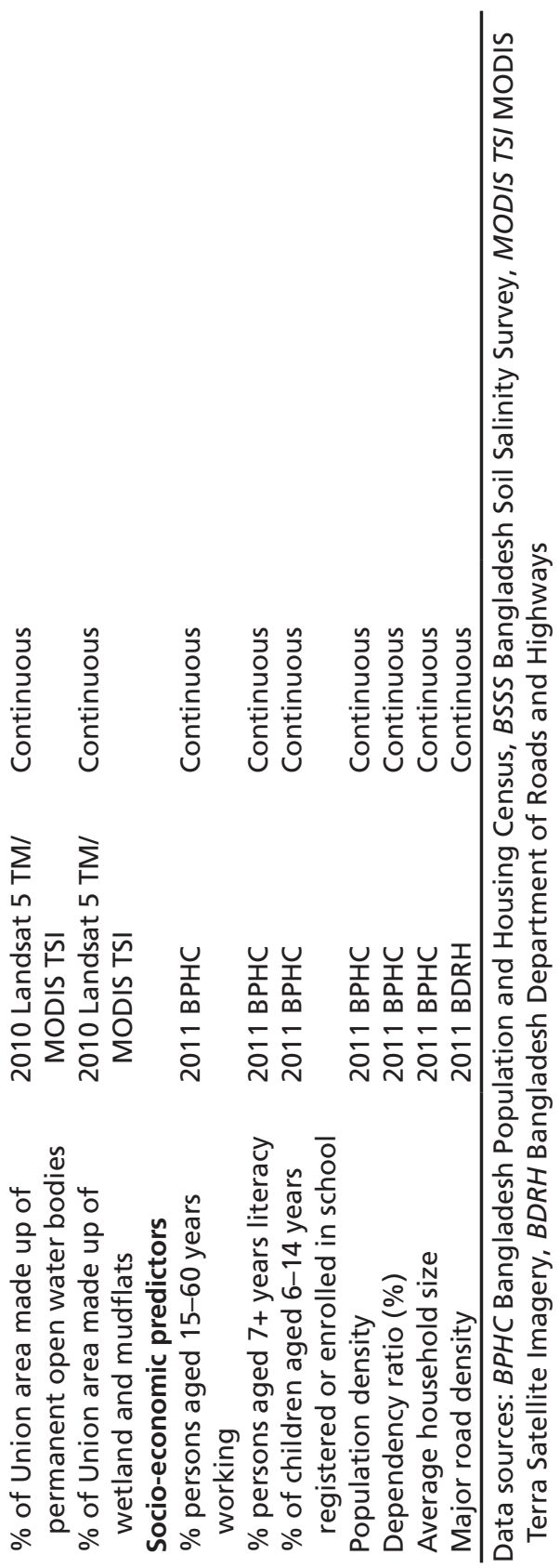




\subsubsection{Methods}

To examine the extent of spatial clustering in asset poverty, the join-count spatial autocorrelation technique is used to examine whether the observed spatial patterns of asset poverty amongst the Unions in the study area are significantly random or clustered (Cliff and Ord 1981). A Bayesian Geoadditive Semi-parametric (BGS) regression is used to examine the geospatial differentials in asset and the extent to which the socio-economic and environmental predictors are associative with the observed spatial differentials in asset poverty (Brezger et al. 2005). The BGS techniques were adopted for this analysis because it allows for the unobserved spatial heterogeneity (both spatially structured and unstructured) to be accounted for as well as the simultaneous estimation of non-linear effects of continuous covariates as well as fixed effects of categorical and continuous covariates in addition to the spatial effects (Brezger et al. 2005).

The outcome variable of interest 'asset poverty' $\mathrm{y}_{i}$ is coded 1 if a Union is in the bottom quintile of the score and 0 otherwise. The outcome variable $\mathrm{y}_{i}$ follows a binomial distribution with parameters $\mathrm{n}_{i}$ and $\pi_{i}$, that is $\mathrm{y}_{i}-\mathrm{B}\left(\mathrm{n}_{i}, \pi_{i}\right)$, where $\pi_{i}$ is the probability of a Union being in the bottom quintile and $\mathrm{n}_{i}$ is the number of Unions in the study area. The model linking the probabilities of a Union being in the bottom quintile with the predictors follows a logistic model of the form:

$$
\pi_{i}=\mathrm{P}\left(\mathrm{y}_{i} 1 \mid \eta_{i}\right)=\frac{\exp \left(\eta_{i}\right)}{1+\exp \left(\eta_{i}\right)}
$$

where $\eta_{i}$ is the predictor of interest. With a vector $x_{i}^{\prime}=\left(x_{i 1}, \ldots,, x_{i k}\right)^{\prime}$ of $k$ continuous covariates and $\lambda_{i}^{\prime}=\left(\lambda_{i 1}, \ldots \lambda_{i d}\right)^{\prime}$ a vector of $d$ categorical covariates, then predictor $\eta_{i}$ can be specified as:

$$
\eta_{i}=\alpha \lambda_{i}^{\prime}+\beta x_{i}^{\prime}
$$

where $\alpha$ is a $d$-dimensional vector of unknown regression coefficients for the categorical covariates $\lambda_{i}^{\prime}, \beta$ is a $k$-dimensional vector of unknown 
regression coefficients for the continuous covariates $\mathrm{x}_{i}^{\prime}$. To account for non-linear effects of the continuous covariates and spatial dependence in asset wealth, the BGS framework which replaces the strictly linear predictors with flexible semi-parametric predictors was adopted. The BGS model is then specified as shown in Eq. 21.3:

$$
\eta_{i}=\alpha \lambda_{i}^{\prime}+f_{k} x_{i k}^{\prime}+f^{\mathrm{spat}\left(S_{i}\right)}
$$

where $f_{k}(\mathrm{x})$ are non-linear smoothing function of the continuous variables $x_{i k}$ and $f^{\text {spat }\left(S_{i}\right)}$ accounts for unobserved spatial heterogeneity at location $i(i=1, \ldots, S)$, some of which may be spatially structured and others unstructured. The spatially structured effects show the effect of location by assuming that geographically close areas are more similar than distant areas, whilst the unstructured spatial effect accounts for spatial randomness in the model. Then, Eq. 21.4 can be specified as:

$$
\eta_{i}=\alpha \lambda_{i}^{\prime}+f_{k} x_{i k}^{\prime}+f^{\mathrm{str}\left(S_{i}\right)}+f^{\mathrm{unstr}\left(S_{i}\right)}
$$

where $f^{\text {str }}$ is the structured spatial effects and $f^{\text {unstr }}$ is the unstructured spatial effects and $f^{\text {spat }\left(S_{i}\right)}=f^{\text {str }}+f^{\text {unstr }}$. In the case of this study, the spatially structured effects depict the extent of clustering of asset poverty and the influence of unaccounted predictor variables that themselves may be spatially clustered or random. The smooth effects of continuous factors are modelled with P-spline priors, whilst the spatial effects are modelled using Markov random field priors.

\subsection{Results}

The geospatial patterns in poverty derived using ownership of assets and amenities are shown in Fig. 21.2. The figure shows a strong clustering of asset poverty in the Bhola district and the Unions close to the Sundarbans. More than half (58.2 per cent) of all the Unions in the Bhola district are classified in the bottom quintile. The Pirojpur district recorded the second 


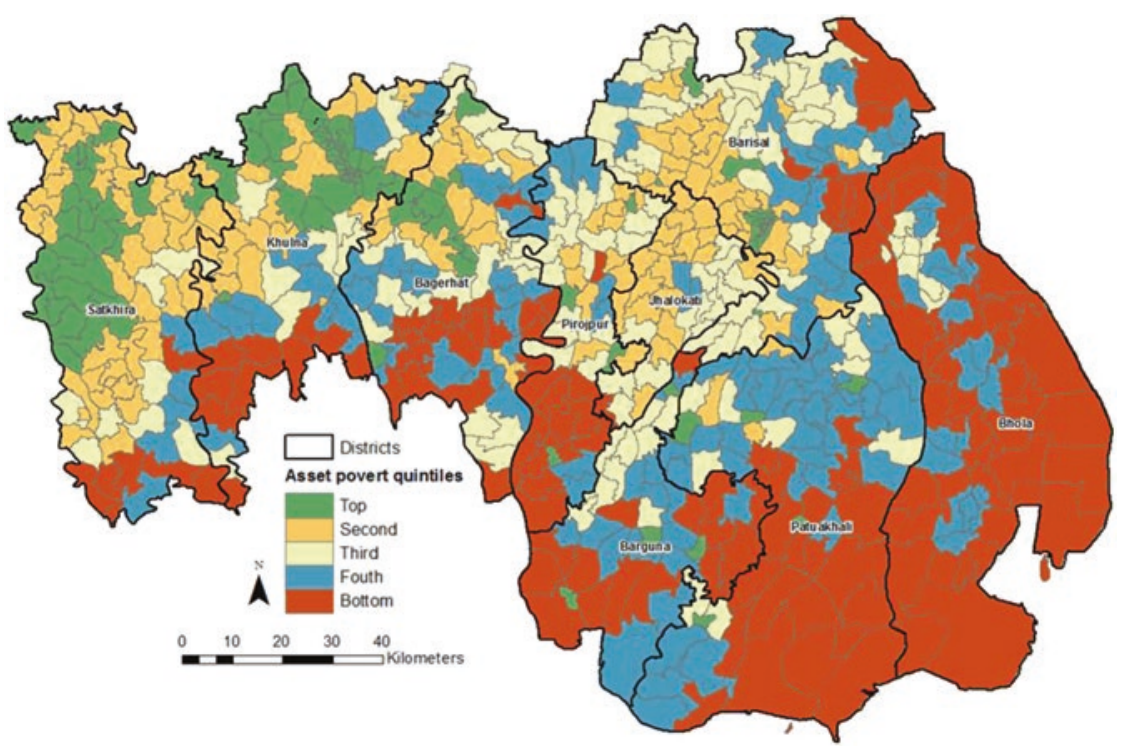

Fig. 21.2 Geospatial variations in asset poverty in the GBM delta of Bangladesh (Reproduced from Amoako Johnson et al. 2016 under Creative Commons Attribution 4.0 International License (http://creativecommons.org/licenses/by/4.0/))

highest percentage (34.9 per cent) of Unions in the bottom quintile. About a quarter of all Unions in the Barguna (25.9 per cent), Patuakhali (25.6 per cent) and Bagerhat (25.0 per cent) districts are also in the bottom quintile. Asset poverty is lowest in the Unions in Jhalokati (2.9 per cent), Barisal (5.7 per cent), Satkhira (9.5 per cent) and Khulna (9.7 per cent) districts where less than one-tenth of Unions in those districts are in the bottom quintile. A joint count spatial autocorrelation analysis showed that Unions in the bottom quintile are nearly three times more likely to be neighbours than would be expected under a random spatial pattern $(\mathrm{Z}[\mathrm{BW}]=-18.87, p<0.05)$. This demonstrates that the poorest Unions are more concentrated in some parts of the study area (see Fig. 21.2).

Table 21.2 shows the posterior odds ratios and their corresponding 95 per cent credible intervals of the effect of the socio-economic and environmental predictors on poverty, after controlling for the location (the divisional administrative effect and rural/urban status of the Union) effects. Only predictors significant at the five per cent significance $(p<0.05)$ level 
Table 21.2 Estimated posterior odds ratios and their corresponding 95 per cent credible intervals of the associative effects of the environmental and socio-economic predictors on poverty

\begin{tabular}{|c|c|c|c|c|}
\hline \multirow[b]{2}{*}{ Primary and control variables } & \multirow[b]{2}{*}{$\begin{array}{l}\text { Odds } \\
\text { ratio }\end{array}$} & \multicolumn{2}{|c|}{$95 \%$ posterior $\mathrm{Cl}$} & \multirow[b]{2}{*}{$\begin{array}{l}\text { Significant } \\
\text { at } p<0.05\end{array}$} \\
\hline & & $\begin{array}{l}\text { Lower } \\
\text { bound }\end{array}$ & $\begin{array}{l}\text { Upper } \\
\text { bound }\end{array}$ & \\
\hline \multicolumn{5}{|l|}{ Location effect } \\
\hline \multicolumn{5}{|l|}{ Division } \\
\hline Barisal & 1.00 & & & \\
\hline Khulna & 0.71 & 0.07 & 7.80 & No \\
\hline \multicolumn{5}{|l|}{ Type of Union } \\
\hline Urban & 1.00 & & & \\
\hline Rural & 1.89 & 0.52 & 6.88 & No \\
\hline \multirow{2}{*}{\multicolumn{5}{|c|}{$\begin{array}{l}\text { Environmental predictors } \\
\text { Intensity and extent of salinity } \\
\text { intrusion (\% Union area) }\end{array}$}} \\
\hline & & & & \\
\hline $2.0-4.0 \mathrm{dS} / \mathrm{m}$ salinity & 1.01 & 0.98 & 1.04 & No \\
\hline 4.1-8.0 dS/m salinity & 1.04 & 1.01 & 1.07 & Yes \\
\hline $8.1-12.0 \mathrm{dS} / \mathrm{m}$ salinity & 1.04 & 1.01 & 1.08 & Yes \\
\hline$>12 \mathrm{dS} / \mathrm{m}$ salinity & 1.07 & 1.01 & 1.14 & Yes \\
\hline \multicolumn{5}{|c|}{ Union area used for brackish shrimp farming } \\
\hline None & 1.00 & & & \\
\hline Low (less than 1 per cent) & 1.36 & 0.36 & 5.14 & No \\
\hline Moderate (1-10 per cent) & 1.79 & 0.14 & 23.49 & No \\
\hline High (greater than 10 per cent) & 0.30 & 0.01 & 8.85 & No \\
\hline \multicolumn{5}{|c|}{ Union area for freshwater prawn farming } \\
\hline None & 1.00 & & & \\
\hline Low (less than 1 per cent) & 0.66 & 0.16 & 2.70 & No \\
\hline High (greater than 1 per cent) & 0.41 & 0.01 & 16.22 & No \\
\hline \multicolumn{5}{|l|}{ Mangroves } \\
\hline Unions with no mangrove & 1.00 & & & \\
\hline Unions with mangrove & 6.05 & 1.35 & 27.16 & Yes \\
\hline Waterlogged agricultural land & 1.02 & 1.00 & 1.05 & Yes \\
\hline Permanent open water bodies & 1.03 & 1.00 & 1.06 & Yes \\
\hline Wetland and mudflats & Non-linear & & & Yes \\
\hline \multicolumn{5}{|l|}{ Socio-economic predictors } \\
\hline$\% 15-64$ years employed & Non-linear & & & Yes \\
\hline $\begin{array}{l}\% 15 \text { years or older who are } \\
\text { literate }\end{array}$ & 0.90 & 0.83 & 0.98 & Yes \\
\hline$\%$ 6-14-year-olds in school & 0.84 & 0.73 & 0.98 & Yes \\
\hline Major road density within Union & 0.01 & 0.00 & 0.45 & Yes \\
\hline
\end{tabular}


are retained in the model, except for the shrimp farming because of its perceived economic importance and an alternative coping mechanism for salinity intrusion in the delta. The posterior odds ratios show that the divisional administrative effect and rural/urban status of the Unions are not significantly associated with poverty. For environmental predictors, the results show that whilst high levels (greater than $4 \mathrm{ds} / \mathrm{m}$ ) of soil salinity in a Union are significantly associated with the probability of a Union being poor, areas used for both brackish shrimp and freshwater prawn farming are not. The estimated posterior odds ratios show that increasing intensity of soil salinity increases the odds of Union being poor. This suggests that whilst poverty is pronounced in Unions affected by high levels of salinity, large shrimp farms do not reduce the incidence of asset poverty.

The results further show that Unions with mangroves are six times more likely to be in the poorest quintile when compared with Unions with no mangrove. For permanent open water bodies, the results show that the higher percentage of permanent open water bodies within a Union, the higher the odds of the Union being in the poorest quintile. On average, if permanent water body area within a Union increases by one per cent, the odds of the Union being in the poorest quintile increases by 1.03 . Similarly, the higher the wetland and mudflats area in a Union, the higher the likelihood of the Union being poor, however, the relationship is not linear.

Considering socio-economic factors, the results show that employment, literacy, school attendance and access to major road with a Union are significantly associated with poverty. The posterior odds ratios show that increase in employment rate, adult literacy and school attendance are all associated with a decline in the odds of a Union being poor (Table 21.2). Also, the higher the density of major roads within a Union, the lower the odds of the Union being poor.

The posterior mode of the structured spatial effects and their corresponding posterior probabilities at the 95 per cent nominal level are used to examine the spatial drivers of poverty. The posterior mode of the structured spatial effects could be used to identify Unions where asset poverty is high, where they are low and where they are trivial. To identify the spatial drivers of poverty, a sequential model building approach was adopted by first including the environmental predictors in the fitted 
model, accounting for the location effects, followed by the socio-economic predictors. The posterior probabilities are used to identify the spatial correlations of the predictors with poverty by examining Unions where the estimated posterior mode of the structured spatial effects become statistically non-significant after covariates are added to the model.

Figure 21.3 shows the spatial correlates of asset poverty for the poorest Unions in the GBM delta based on the asset score. The results show that the environmental controls exhibit significant geospatial associations with asset poverty predominantly with Unions close to the Sundarbans in the Satkhira and Khulna and Bagerhat districts, as well as those in the Barguna, Patuakhali and Pirojpur districts.

The socio-economic predictors were significantly associated with asset poverty for Unions in the Bhola and Patuakhali districts, as well as a few Unions in the Barisal district. The socio-economic factors are associated with asset poverty in 34 of the 39 Unions in the bottom quintile in the

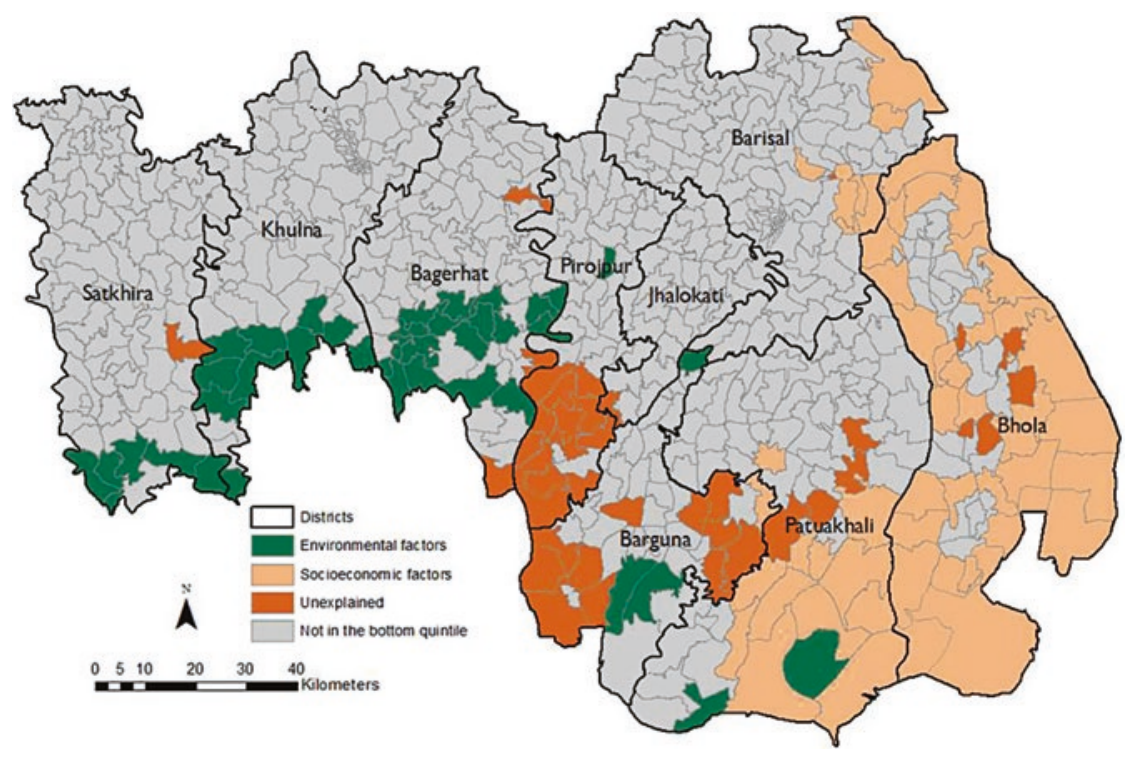

Fig. 21.3 Spatial correlates of poverty amongst Unions in the bottom quintile (Reproduced from Amoako Johnson et al. 2016 under Creative Commons Attribution 4.0 International License (http://creativecommons.org/licenses/by/4.0/)) 
Bhola district, making up about half of all the Unions in the district. In the Patuakhali district, the socio-economic factors are associated with asset poverty in 12 of the 18 Unions in the bottom quintile. The socio-economic factors are also significantly associated with asset poverty in six Unions in the Barisal district-Dhul Khola, Hizla Gaurabdi, Alimabad, Char Gopalpur, Jangalia and Bhasan Char Unions and also the Atharagashia Union in the Barguna district.

\subsection{Discussion}

The analysis conducted in this research illustrates that the benefits of integrating census data at lower geographic units are beneficial for designing and promoting policy-relevant research and the development of sustainable poverty-relevant programmes and targeted interventions. Using census data, this research has been able to explore the geospatial differentials in asset poverty, an important indicator and correlate of chronic poverty and lack of human capital (McKay and Lawson 2003; Cooper and Bird 2012; Stein and Horn 2012; Wietzke 2015), and provide input into the integrated modelling described in Chap. 28. Linking census and environmental data derived from Landsat 5 TM, MODIS TSI and Soil Salinity Survey, the research has explored the spatial correlates of poverty in the GBM delta.

The results show a strong clustering of poverty in the GBM delta, predominantly clustered amongst Unions in the Bhola, Bagerhat, Barguna, Patuakhali and Pirojpur districts. The multivariate analysis revealed that the environmental predictors-intensity and extent of salinity intrusion in a Union, presence of mangrove forest, waterlogged agricultural land, permanent open water bodies and wetland and mudflats-are significantly associated with Union level poverty. Whilst increasing intensity of salinity intrusion is significantly associated with poverty, the results also show that both large brackish shrimp and freshwater prawn farms do not impact on poverty in the GBM delta. This reveals that the impact of shrimp farming on alleviating poverty amongst the local population is trivial. The strong association identified between salinity intrusion and poverty could be attributed to loss of arable land, reduced agricultural 
productivity and income, food insecurity, rural unemployment, social unrest, conflicts and forced migration (Paul and Vogl 2011; Swapan and Gavin 2011; Hossain et al. 2013; Sá et al. 2013).

Socio-economic predictors, employment rate, adult literacy and school attendance are also significant predictors of poverty as well as access to major roads. The results show that increased employment rate, adult literacy, school attendance and access to major roads reduce the odds of a Union being poor.

The overall finding of the research is that the socio-economic and environmental drivers of poverty in the GBM delta are discernible spatially. As captured in the Bangladesh Government coastal zone policy, the coastal zone is slow in socio-economic development and lacks the resources to cope with environment deterioration and hazards (MoWR 2005). As such policy formulation aimed at improving the well-being of residents of the GBM delta should be geospatially focused and targeted. These findings provide relevant input to addressing the geospatial inequalities in poverty in the GBM delta in the government's coastal zone policy plan.

\section{Note}

1. Available at https://unstats.un.org/unsd/demographic/sources/census/ censusdates.htm

\section{References}

Ahsan, M. 2010. Saline soils of Bangladesh. Dhaka: Soil Resource Development Institute, Ministry of Agriculture, Government of the People's Republic of Bangladesh. http://srdi.portal.gov.bd/sites/default/files/files/srdi.portal.gov. bd/publications/bc598e7a_df21_49ee_882e_0302c974015f/Soil\%20 salinity\%20report-Nov\%202010.pdf. Accessed 6 Sept 2016.

Amoako Johnson, F., C.W. Hutton, D. Hornby, A.N. Lázár, and A. Mukhopadhyay. 2016. Is shrimp farming a successful adaptation to salinity intrusion? A geospatial associative analysis of poverty in the populous 
Ganges-Brahmaputra-Meghna Delta of Bangladesh. Sustainability Science 11 (3): 423-439. https://doi.org/10.1007/s11625-016-0356-6.

BBS. 2012. Bangladesh population and housing census 2011 - Socio-economic and demographic report. Report national series. Vol. 4. Dhaka, Bangladesh: Bangladesh Bureau of Statistics (BBS) and Statistics and Informatics Division (SID), Ministry of Planning, Government of the People's Republic of Bangladesh. http://www.bbs.gov.bd/PageSearchContent.aspx?key=census\% 202011. Accessed 7 July 2016.

Bern, C., J. Sniezek, G.M. Mathbor, M.S. Siddiqi, C. Ronsmans, A.M.R. Chowdhury, A.E. Choudhury, K. Islam, M. Bennish, E. Noji, and R.I. Glass. 1994. Risk factors for mortality in the Bangladesh cyclone of 1991. Bulletin of the World Health Organisation 71 (1): 73-78.

Biswas, A.K. 2008. Management of Ganges-Brahmaputra-Meghna system: Way forward. In Management of transboundary rivers and lakes, ed. O. Varis, A.K. Biswas, and C. Tortajada, 143-164. Berlin: Springer.

Brezger, A., T. Kneib, and S. Lang. 2005. BayesX: Analyzing Bayesian structured additive regression models. Journal of Statistical Software 14 (11): 1-22.

Cliff, A.D., and J.K. Ord. 1981. Spatial processes, models and applications. London: Pion.

Cooper, E., and K. Bird. 2012. Inheritance: A gendered and intergenerational dimension of poverty. Development Policy Review 30 (5): 527-541. https:// doi.org/10.1111/j.1467-7679.2012.00587.x.

Daw, T.M., C.C. Hicks, K. Brown, T. Chaigneau, F.A. Januchowski-Hartley, W.W.L. Cheung, S. Rosendo, B. Crona, S. Coulthard, C. Sandbrook, C. Perry, S. Bandeira, N.A. Muthiga, B. Schulte-Herbrüggen, J. Bosire, and T.R. McClanahan. 2016. Elasticity in ecosystem services: Exploring the variable relationship between ecosystems and human well-being. Ecology and Society 21 (2). https://doi.org/10.5751/ES-08173-210211.

FAO. 2015. National aquaculture sector overview: Bangladesh. Rome: Food and Agriculture Organization of the United Nations (FAO), Fisheries and Aquaculture.

Filmer, D., and L.H. Pritchett. 2001. Estimating wealth effects without expenditure data - Or tears: An application to educational enrollments in states of India. Demography 38 (1): 115-132. https://doi.org/10.2307/3088292.

GFDRR, UNDP, and EU. 2014. Planning and implementation of post-Sidr housing recovery: Practice, lessons and future implications: Recovery framework case study. Dhaka, Bangladesh: Global Facility for Disaster Reduction and Recovery (GFDRR) of the World Bank, United Nations Development Program (UNDP) and the European Union (EU). 
Hossain, M.S., M.J. Uddin, and A.N.M. Fakhruddin. 2013. Impacts of shrimp farming on the coastal environment of Bangladesh and approach for management. Reviews in Environmental Science and Bio-Technology 12 (3): 313-332. https://doi.org/10.1007/s11157-013-9311-5.

Islam, D., J. Sayeed, and N. Hossain. 2016. On determinants of poverty and inequality in Bangladesh. Journal of Poverty: 1-20. https://doi.org/10.1080/1 0875549.2016 .1204646$.

Jones, B., and J. Andrey. 2007. Vulnerability index construction: Methodological choices and their influence on identifying vulnerable neighborhoods. International Journal of Emergency Management 42 (2): 269-295. https://doi. org/10.1504/IJEM.2007.013994.

McKay, A., and D. Lawson. 2003. Assessing the extent and nature of chronic poverty in low income countries: Issues and evidence. World Development 31 (3): 425-439. https://doi.org/10.1016/s0305-750x(02)00221-8.

Meyer, B.D., and J.X. Sullivan. 2003. Measuring the well-being of the poor using income and consumption. Journal of Human Resources 38: 1180-1220. https://doi.org/10.2307/3558985.

MoHFW. 2012. Health Bulletin 2012. Dhaka: Ministry of Health and Family Welfare, Government of the People's Republic of Bangladesh.

MoWR. 2005. Coastal zone policy. Dhaka: Ministry of Water Resources (MoWR), Government of the People's Republic of Bangladesh. http://lib. pmo.gov.bd/legalms/pdf/Costal-Zone-Policy-2005.pdf. Accessed 20 Apr 2017.

Mukhopadhyay, A., P. Mondal, J. Barik, S.M. Chowdhury, T. Ghosh, and S. Hazra. 2015. Changes in mangrove species assemblages and future prediction of the Bangladesh Sundarbans using Markov chain model and cellular automata. Environmental Science-Processes and Impacts 17 (6): 1111-1117. https://doi.org/10.1039/c4em00611a.

Nenova, T. 2010. Expanding housing finance to the underserved in South Asia: Market review and forward agenda. Washington, DC: The World Bank. https://openknowledge.worldbank.org/handle/10986/2475. Accessed 13 Mar 2017.

Nicholls, R.J., C.W. Hutton, A.N. Lázár, A. Allan, W.N. Adger, H. Adams, J. Wolf, M. Rahman, and M. Salehin. 2016. Integrated assessment of social and environmental sustainability dynamics in the Ganges-BrahmaputraMeghna delta, Bangladesh. Estuarine, Coastal and Shelf Science 183, Part B: 370-381. https://doi.org/10.1016/j.ecss.2016.08.017. 
Nicoletti, C., F. Peracchi, and F. Foliano. 2011. Estimating income poverty in the presence of missing data and measurement error. Journal of Business and Economic Statistics 29 (1): 61-72. https://doi.org/10.1198/jbes.2010.07185.

Panday, P.K. 2011. Local government system in Bangladesh: How far is it decentralised? Journal of Local Self-Government 9 (3): 205-230.

Paul, B.G., and C.R. Vogl. 2011. Impacts of shrimp farming in Bangladesh: Challenges and alternatives. Ocean and Coastal Management 54 (3): 201-211. https://doi.org/10.1016/j.ocecoaman.2010.12.001.

Rahman, M.M., V.R. Giedraitis, L.S. Lieberman, T. Akhtar, and V. Taminskiene. 2013. Shrimp cultivation with water salinity in Bangladesh: The implications of an ecological model. Universal Journal of Public Health 1 (3): 131-142. http://dx.doi.org/10.13189/ujph.2013.010313.

Rutstein, S.O., and K. Johnson. 2004. The DHS wealth index. Demographic and Health Surveys (DHS) comparative reports no. 6. Calverton: ORC Macro.

Sá, T., R. Sousa, Í. Rocha, G. Lima, and F. Costa. 2013. Brackish shrimp farming in Northeastern Brazil: The environmental and socio-economic impacts and sustainability. Natural Resources 4 (8): 538-550. https://doi.org/10.4236/ nr.2013.48065.

Sohel, N., M. Vahter, M. Ali, M. Rahman, A. Rahman, P.K. Streatfield, P.S. Kanaroglou, and L.Å. Persson. 2010. Spatial patterns of fetal loss and infant death in an arsenic-affected area in Bangladesh. International Journal of Health Geographics 9 (1): 53. https://doi.org/10.1186/1476-072X-9-53.

Stein, A., and P. Horn. 2012. Asset accumulation: An alternative approach to achieving the Millennium Development Goals. Development Policy Review 30 (6): 663-680. https://doi.org/10.1111/j.1467-7679.2012.00593.x.

Suich, H., C. Howe, and G. Mace. 2015. Ecosystem services and poverty alleviation: A review of the empirical links. Ecosystem Services 12: 137-147. https://doi.org/10.1016/j.ecoser.2015.02.005.

Swapan, M.S.H., and M. Gavin. 2011. A desert in the delta: Participatory assessment of changing livelihoods induced by commercial shrimp farming in Southwest Bangladesh. Ocean and Coastal Management 54 (1): 45-54. https://doi.org/10.1016/j.ocecoaman.2010.10.011.

Szabo, S., E. Brondizio, F.G. Renaud, S. Hetrick, R.J. Nicholls, Z. Matthews, Z. Tessler, A. Tejedor, Z. Sebesvari, E. Foufoula-Georgiou, S. da Costa, and J.A. Dearing. 2016. Population dynamics, delta vulnerability and environmental change: Comparison of the Mekong, Ganges-Brahmaputra and Amazon delta regions. Sustainability Science 11 (4): 539-554. https://doi. org/10.1007/s11625-016-0372-6. 
Wietzke, F.B. 2015. Who is poorest? An asset-based analysis of multidimensional wellbeing. Development Policy Review 33 (1): 33-59. https://doi. org/10.1111/dpr.12091.

Open Access This chapter is licensed under the terms of the Creative Commons Attribution 4.0 International License (http://creativecommons.org/licenses/ by/4.0/), which permits use, sharing, adaptation, distribution and reproduction in any medium or format, as long as you give appropriate credit to the original author(s) and the source, provide a link to the Creative Commons license and indicate if changes were made.

The images or other third party material in this chapter are included in the chapter's Creative Commons license, unless indicated otherwise in a credit line to the material. If material is not included in the chapter's Creative Commons license and your intended use is not permitted by statutory regulation or exceeds the permitted use, you will need to obtain permission directly from the copyright holder.

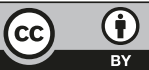

